\title{
Orthodontic archwire composition and phase analyses by neutron spectroscopy
}

\author{
Kun V. TIAN ${ }^{1,2,3}$, Giulia FESTA ${ }^{2,4,5,6}$, Francesco BASOLI ${ }^{7}$, Giuseppina LAGANÀ ${ }^{1,8}$, Antonella SCHERILLO ${ }^{9}$ \\ Carla ANDREANI ${ }^{2,4,5,10}$, Patrizio BOLLERO ${ }^{11}$, Silvia LICOCCIA ${ }^{1,2}$, Roberto SENES| $\left.\right|^{2,4,5,10}$ and Paola COZZA ${ }^{2,8}$ \\ ${ }^{1}$ Department of Chemical Science and Technologies, University of Rome Tor Vergata, Rome, Italy \\ ${ }^{2}$ NAST Centre, University of Rome Tor Vergata, Rome, Italy \\ ${ }^{3}$ Global Institute of Computational Molecular and Materials Science, Toronto/Budapest/Beijing, Canada/Hungary/P.R. China \\ ${ }^{4}$ Department of Physics, University of Rome Tor Vergata, Rome, Italy \\ ${ }^{5}$ Enrico Fermi Historic Museum of Physics and Research Center, Rome, Italy \\ ${ }^{6}$ CNR-IC Institute of Crystallography, Bari, Italy \\ ${ }^{7}$ Department of Engineering, Campus Bio-Medico University of Rome, Rome, Italy \\ ${ }^{8}$ Department of Clinical Sciences and Translational Medicine, University of Rome Tor Vergata, Rome, Italy \\ ${ }^{9}$ Science and Technology Facility Council, ISIS Pulsed Neutron and Muon Source, Didcot, United Kingdom \\ ${ }^{10} \mathrm{CNR}$-IPCF Institute for the Chemical and Physical Processes, Messina, Italy \\ ${ }^{11}$ The Unit of Oral Pathology, Department of Systems Medicine, University of Rome Tor Vergata, Rome, Italy \\ Corresponding authors, Kun V.TIAN; E-mail: kun.tian@uniroma2.it, Roberto SENESI; E-mail: roberto.senesi@uniroma2.it
}

\begin{abstract}
Quantitative metallurgical and phase analyses employing neutron diffraction technique were conducted on two as-received commercial rectangular austenitic stainless steel orthodontic archwires, G\&H and Azdent, $0.43 \times 0.64 \mathrm{~mm}(0.017 \times 0.025$ inch). Results showed a bi-phase structure containing martensitic phase ( $45.67 \%$ for G\&H and $6.62 \%$ for Azdent) in addition to the expected metastable austenite. The former may be a strain-induced phase-transformation arising during the cold working process of wire fabrication. Further neutron resonance capture analysis determinations provided atomic and isotopic compositions, including alloying elements in each sample, complementary to the results of traditional energy dispersive X-ray spectroscopy. Together, these results assist in relating commercial alloying recipes and processing histories with mechanical performance, strength and ductility in particular.
\end{abstract}

Keywords: Orthodontic archwire, Stainless steel, Martensite, Phase transformation, Neutron diffraction

\section{INTRODUCTION}

Since its inception in $1913^{1)}$, stainless steel (SS) has become an indispensable material in numerous industrial and medical applications due to its mechanical properties and resistance to corrosion ${ }^{2,3)}$. The refinement of material-drawing processes in the 1930s allowed for SS orthodontic archwires to be formed with reduced cross-sections $^{4)}$, quickly becoming a viable alternative to Angle's gold archwires ${ }^{5)}$ that originally dominated the field. By the 1950s, 300-series SS alloys were exclusively adopted in the treatment of malocclusions. Type 304 austenitic $18-8$ SS alloys $(18 \% \mathrm{Cr}$ and $\sim 8 \% \mathrm{Ni})$ are the most commonly used alloys for orthodontic wires ${ }^{6}$. The chromium forms a coherent, uniform and nonporous oxide $\left(\mathrm{Cr}_{2} \mathrm{O}_{3}\right)$ layer passivating the surface to oxidative attack, giving the alloy's stainless label ${ }^{4,7)}$. They have remained popular with orthodontists ${ }^{8,9)}$ even after the introduction of other archwire alloys, including cobaltchromium $^{10)}$, super-elastic nickel-titanium ${ }^{11)}$ and betatitanium $^{12)}$, each with their specific set of properties. Relative to other archwire alloys, SSs have low cost, low coefficient of friction, high stiffness, high strength, low working range, intermediate springback, etc. ${ }^{4}$. They are versatile and can be used in all stages of orthodontic treatments ${ }^{13)}$.

Color figures can be viewed in the online issue, which is available at J-STAGE.

Received May 31, 2016: Accepted Oct 3, 2016

doi:10.4012/dmj.2016-206 JOI JST.JSTAGE/dmj/2016-206
Although much research has been done on the mechanical properties of austenitic SS archwires ${ }^{14-18)}$, fundamental question about the metallurgical structure that determines the mechanical properties still remains ${ }^{19)}$. The few X-ray diffraction studies conducted on SS archwires ${ }^{19-21)}$ have discovered the presence of a martensitic phase ${ }^{19)}$. This phase transformation impairs the mechanical performance of the archwires by significantly reducing the modulus of elasticity and ductility ${ }^{21-23)}$. Thus, the ability to measure and control the relative proportions of the two phases is essential for clinical practice and materials research, in order to optimise the wires with better force delivery properties without losing ductility ${ }^{20)}$. However, the usage of conventional X-ray Diffraction (XRD) limits our understanding of the precise metallurgic structure of these important materials because X-ray beams interact strongly with metallic materials so they penetrate only a small depth. Essentially XRD is sensitive to the nearsurface layer (few $\mu \mathrm{m})^{24)}$. Also, for samples with strongly oriented texture, like the archwires, quantitative phase analysis with XRD based on the random crystal model cannot be carried out reliably without relying on sophisticated corrections for preferred orientation ${ }^{20,25)}$. Thus timing is perfect for introducing new technique.

Neutron Diffraction (ND) can overcome the above limitations of XRD. Neutron beams interact only weakly with matter $^{26)}$ so they penetrate more deeply. For 
example, their penetration length in steels exceeds $10 \mathrm{~mm}^{27)}$. And they are effective for studying bulk properties. The diffraction process is the reflection of the incident neutron beams by the crystal planes $h k l$. Diffractometers at a spallation source are based primarily on the determination of the neutron energy for a 'white beam', measuring their Time of Flight (TOF), which is the time lapse from the neutron leaving the source to when a scattered/emitted particle reaches the detector ${ }^{28)}$. The Bragg's law, $n \lambda=2 d_{\mathrm{hll}} \sin \theta$ can be rewritten for the TOF technique relating TOF with $d$-spacing (distance between adjacent planes):

$$
(T O F)_{h k l}=\frac{2 m_{n}}{h} L d_{h k l} \sin \theta_{0}
$$

where $m_{\mathrm{n}}$ is the mass of a neutron, $h$ is Planck's constant, $L$ is flight path and $\theta_{0}$ is half value of the fixed angle of a specific detector. It has been proven that ND provides reliable quantification of phase composition even in oriented samples ${ }^{25)}$.

Standard energy dispersive X-ray spectroscopy (EDX) as a chemical compositional technique shows similar surface sensitivity as XRD: the signals are from the near-surface region so it is not a bulk analysis technique ${ }^{29)}$. Moreover, many elements have overlapping peaks and some emitted X-rays may not escape the sample and be detected, reducing the accuracy in inhomogeneous samples ${ }^{29)}$.

Neutron Resonance Capture Analysis (NRCA) is a technique for the determination of elemental composition, making use of a pulsed beam of epithermal neutrons and a TOF system to recognize resonances of isotopes in the energy range of $\sim 1 \mathrm{eV}$ to $\sim 10 \mathrm{keV}^{30,31)}$. For many metallic materials, the impinging epithermal neutrons are resonantly captured by the material's nuclei, showing intense peaks in the absorption cross section (probability of a neutron being absorbed by a nucleus). When the nuclei de-excite back to the ground state prompt gamma rays are emitted in a cascade, which are then captured by detectors ${ }^{32)}$. The neutron source pulse and the signal obtained by the detection of the prompt gamma emission mark the TOF (Fig. 1). The resonance energy is calculated from $T O F^{33)}$

$$
E_{r}=\frac{1}{2} m_{n}\left(\frac{L_{0}}{T O F}\right)^{2}
$$

where $m_{\mathrm{n}}$ is the neutron mass and $L_{0}$ is the neutron flight path. Since the resonance energy is characteristic of each element with additional isotopic sensitivity ${ }^{34)}$, the elemental/isotopic composition can then be determined. NRCA is a bulk analytical technique showing its largest sensitivity for metallic and highatomic number elements. Besides being fully nondestructive and non-invasive, NRCA does not require sample treatments nor preparations ${ }^{35)}$.

The aim of the current work is to test the suitability of ND-NRCA techniques in the study of metallurgical

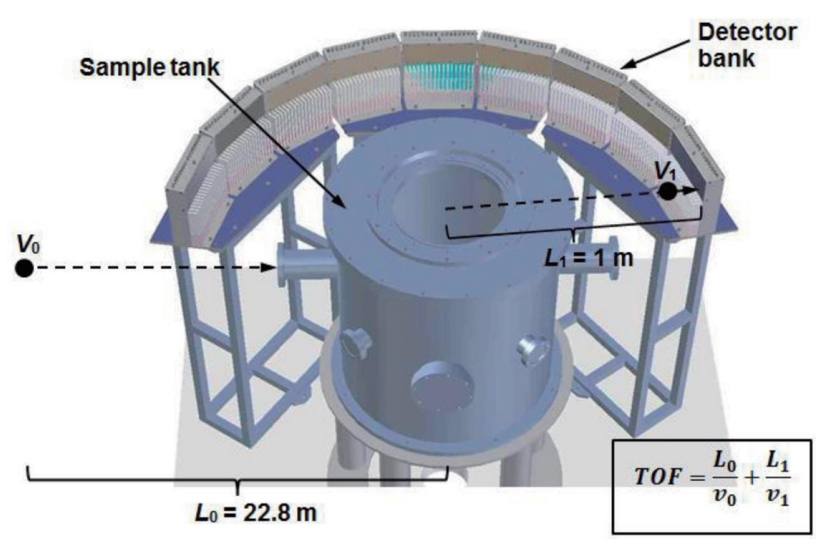

Fig. 1 Schematics of INES instrument diffraction configuration and neutron Time of Flight (TOF).

structure, phase and elemental compositions of orthodontic stainless steel archwires that have borne high degree of cold-working.

\section{MATERIALS AND METHODS}

\section{Materials}

Two commercial brands G\&H (G\&H Wire Company, Franklin, IN, USA) and Azdent (Baistra Industrial, Zhengzhou, China) of rectangular stainless steel orthodontic archwires of size $0.43 \times 0.64 \mathrm{~mm}(0.017 \times 0.025$ inch) were measured in the as-received form.

\section{EDX measurements}

The elemental analysis was performed by a Scanning Electron Microscopy, FE-SEM, Field Emission Scanning Electron Microscope (SUPRA $^{\mathrm{TM}}$ 35, Carl Zeiss SMT, Oberkochen, Germany) equipped with an Energy Dispersive Microanalysis (EDS/EDX, INCAx-sight, 7426, Oxford Instruments, Abingdon, UK). The main operating parameters used in order to achieve the maximum signal were $20 \mathrm{kV}$ gun voltage, $60 \mu \mathrm{m}$ objective aperture and $\sim 8 \mathrm{~mm}$ working distance. Considering the average atomic number of the elements composing the samples even at $20 \mathrm{kV}$ the interaction distance (i.e. penetration depth) would be $\sim 5-10 \mu \mathrm{m}^{28)}$. The elemental analyses were performed at three different positions for each sample in order to verify the homogeneity of the sample composition along the whole wire length.

\section{Simultaneous measurements with INES spectrometer}

The samples were each measured with integrated and simultaneous use of ND and NRCA on the INES (Italian Neutron Experimental Station) diffractometer at the ISIS pulsed neutron and muon source (Rutherford Appleton Laboratory, Harwell, UK). The details of INES have been discussed elsewhere ${ }^{36)}$ and only a brief description will be given here. Figure 1 is a schematic of the INES diffraction configuration. It is equipped with 9 detector banks, each composed by $16{ }^{3} \mathrm{He}$ squashed 
detectors, covering a range of $\sim 160^{\circ}\left(11.6^{\circ}-170.6^{\circ}\right)$ on the horizontal scattering plane. The long primary flight path $\left(L_{0}=22.8 \mathrm{~m}\right)$ determines the good resolving power of the instrument. An Yttrium-Aluminum-Perovskite (YAP) gamma scintillation detector installed above sample tank was used to record the NRCA signals ${ }^{34)}$.

Samples were inserted into an aluminium pocket attached to a metallic rod and loaded into the sample tank. The two samples were measured for 73,435 s and $51,722 \mathrm{~s}$, respectively.

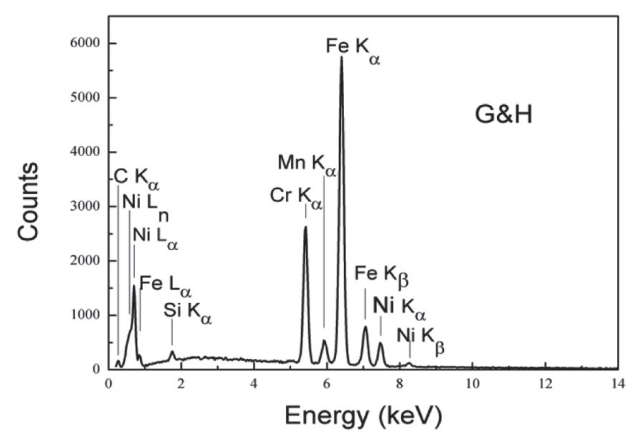

\section{RESULTS}

Elemental composition

Figure 2 depicts the results from the SEM-EDX analyses.

The semi-quantitative elemental composition determined by EDX is tabulated in Table 1.

The main peaks of the NRCA spectra were identified by comparison with the resonance energies related to $(n, \gamma)$ processes provided by the table of

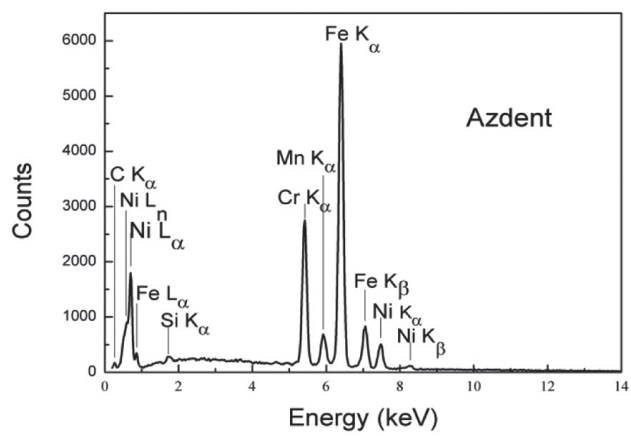

Fig. 2 EDX spectra of G\&H (upper) and Azdent (lower) archwires. The peaks are labelled with the identified elements.

Table 1 Elements and their Wt\% and A\% determined by EDX

\begin{tabular}{lrrrrr}
\hline \multirow{2}{*}{ Element } & \multicolumn{3}{c}{ G\&H } & & \multicolumn{3}{c}{ Azdent } \\
\cline { 2 - 3 } \cline { 5 - 6 } C K & Wt\% & $\mathrm{A} \%$ & & $\mathrm{Wt} \%$ & $\mathrm{~A} \%$ \\
\hline Si K & 4.24 & 16.83 & & 3.68 & 15.16 \\
Cr K & 0.76 & 1.28 & & 0.39 & 0.67 \\
Mn K & 18.87 & 1.12 & 19.04 & 17.84 \\
Fe K & 1.52 & 56.52 & & 66.62 & 2.31 \\
Ni K & 66.38 & 6.68 & 7.67 & 57.70 \\
\hline
\end{tabular}

Table 2 Elements identified from NRCA spectra as well as their TOF $(\mu \mathrm{s})$ and resonance energy $E_{\mathrm{r}}(\mathrm{eV})$ values

\begin{tabular}{|c|c|c|c|c|}
\hline & \multicolumn{2}{|c|}{$\mathrm{G \& H}$} & \multicolumn{2}{|c|}{ Azdent } \\
\hline & $T O F(\mu \mathrm{s}) ; E_{\mathrm{r}}(\mathrm{eV})$ & Amount & $T O F(\mu \mathrm{s}) ; E_{\mathrm{r}}(\mathrm{eV})$ & Amount \\
\hline${ }^{52} \mathrm{Cr}$ & - & - & $41.05 ; 1612.70$ & Minor \\
\hline${ }^{60} \mathrm{Ni}$ & - & - & $45.55 ; 1309.80$ & Minor \\
\hline${ }^{57} \mathrm{Fe}$ & $48.45 ; 1157.70$ & Main & $48.45 ; 1157.70$ & Main \\
\hline${ }^{56} \mathrm{Fe}$ & $48.85 ; 1138.80$ & Main & $48.85 ; 1138.80$ & Main \\
\hline${ }^{63} \mathrm{Cu}$ & $68.45 ; 580.00$ & Minor & - & - \\
\hline${ }^{55} \mathrm{Mn} /{ }^{58} \mathrm{Fe}$ & $91.45 ; 324.94$ & Minor & $90.35 ; 332.90$ & Minor \\
\hline${ }^{59} \mathrm{Co}$ & - & - & $144.35 ; 130.42$ & Minor \\
\hline
\end{tabular}



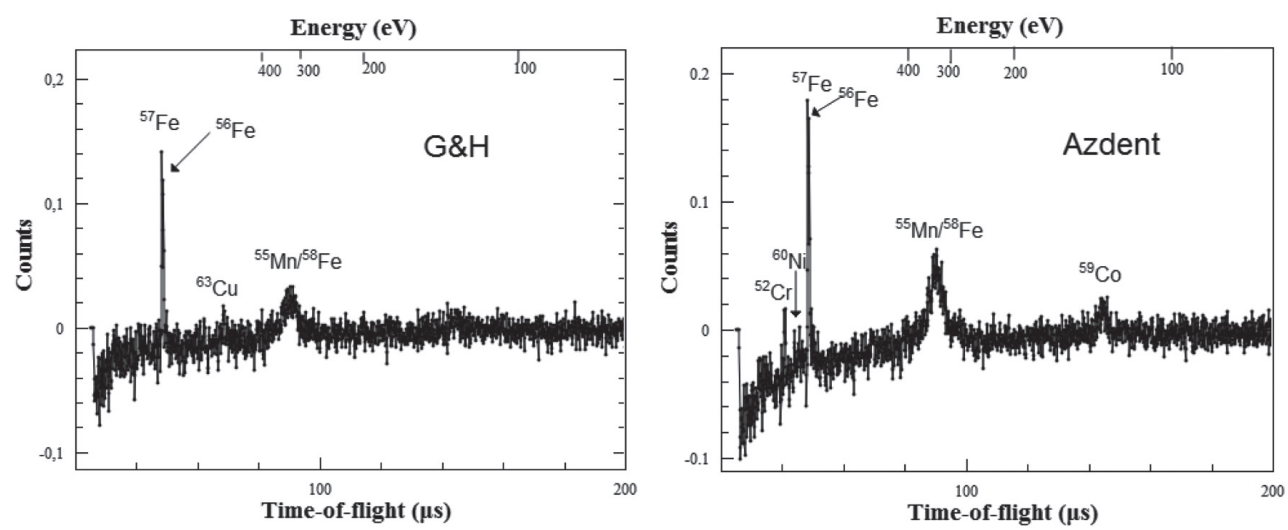

Fig. 3 NRCA (Neutron Resonance Capture Analysis) spectra of G\&H (left) and Azdent (right) archwires.

The detected peaks are labelled with the elemental symbols.

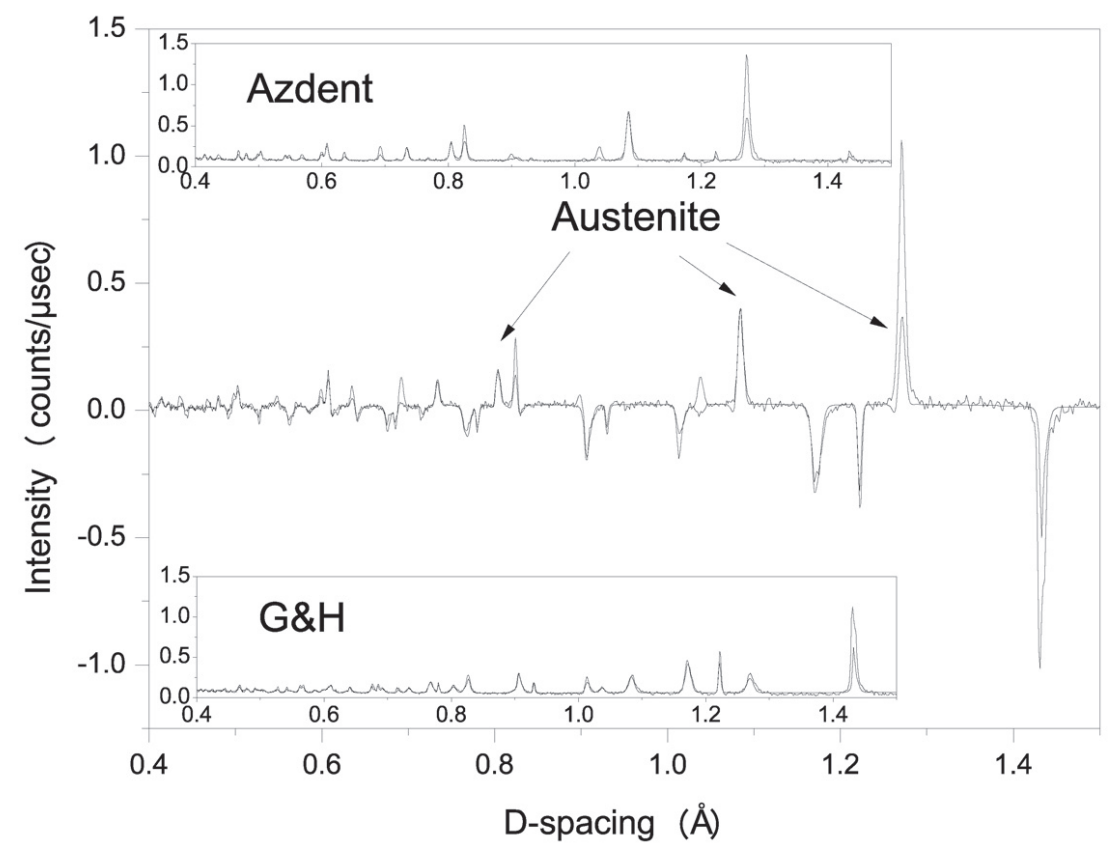

Fig. 4 The difference between Azdent and G\&H diffraction patterns is plotted in black (normalized number of counts/ $\mu$ s as a function of $d$-spacing) and the difference of best fit of data obtained by Rietveld refinement is plotted in blue.

The main austenite diffraction peaks at $\sim 0.8, \sim 1.08$ and $\sim 1.27 \AA$ are labelled to highlight these differences. Inset: diffractograms (black) of the two samples and their best fit of data (blue).

neutron resonances ${ }^{37)}$ and natural isotope abundance was used to determine the isotopes of the elements present in the samples. The determined peaks with their TOF $(\mu \mathrm{s})$ and resonance energy $E_{\mathrm{r}}(\mathrm{eV})$ values are reported in Table 2. A semi-quantitative analysis of the relative atomic percentage of each element (isotope) was carried out by comparing the intensity of each peak in the spectra (Fig. 3) with a chosen reference peak (in this case the ${ }^{57} \mathrm{Fe}$ resonance at $1157.70 \mathrm{eV}$ ) using the following relation ${ }^{36)}$ :

$$
A=\frac{I_{\mathrm{P} 1} \sigma_{2} t_{2}{ }^{2}}{I_{\mathrm{P} 2} \sigma_{1} t_{1}{ }^{2}}
$$

where $I_{\mathrm{P}}$ is the peak maxima intensity, $\sigma$ is the radiative capture cross section of natural elements at the 
Table 3 Structure refinement results from the neutron diffraction data for the two samples: weight fractions of the phases and their unit cell parameters

\begin{tabular}{rcc}
\hline & G\&H & Azdent \\
\hline Austenite & $54.33 \%$ & $93.38 \%$ \\
$\mathrm{a}=\mathrm{b}=\mathrm{c}$ & $3.588370 \AA$ & $3.595628 \AA$ \\
$\alpha=\beta=\gamma$ & $90^{\circ}$ & $90^{\circ}$ \\
Martensite & $45.67 \%$ & $6.62 \%$ \\
$\mathrm{a}=\mathrm{b}=\mathrm{c}$ & $2.868512 \AA$ & $2.874413 \AA$ \\
$\alpha=\beta=\gamma$ & $90^{\circ}$ & $90^{\circ}$ \\
\hline
\end{tabular}

resonance energy and $t$ is the peak position. Subscript 2 refers to the reference peak. The semi-quantitative degree of abundance is also reported in Table 2.

\section{Phase composition}

ND data were analyzed with GSAS (General Structure Analysis System) software ${ }^{38)}$ for the refinement of structural models to powder diffraction data with the EXPGUI interface ${ }^{39}$, using the Rietveld method to determine weight fractions of the main phases. Diffractograms and best fits of the two samples are shown in Fig. 4 together with the difference between them.

The determined weight fractions of the austenite and martensite as well as their unit cell parameters for the two samples are reported in Table 3.

\section{DISCUSSION}

Stainless steel orthodontic archwires are generally manufactured by rolling commercial alloy ingots into long bars with sufficiently small cross-sections and then drawing the bars through series of dies to further reduce the size. Rectangular wires also go through a final rolling stage to form the rectangular cross-sections ${ }^{19}$. Considerable work-hardening occurs during extensive cold-working which makes the alloy hard and brittle. Heat treatments are used to relieve work-hardening.

The wire composition is the same as the commercial ingots. For type 300 austenitic SS $\sim 0.2 \%$ maximum carbon is added for increased hardness and prevention of chromium carbides formation, which will ultimately cultivate corrosion ${ }^{4)}$. $\sim 2 \% \mathrm{Mn}$ is usually added for improved hot ductility ${ }^{1)}$. It is known that EDX cannot effectively quantify light elements like carbon. Here it is seen that unrealistically-high carbon content (Table 1) was detected, which is almost 20 times higher than the standard value. This value should not be regarded on an absolute basis. The increased carbon content could possibly arise from organic surface impurity or carbides formation on the surface. Higher carbon content would result in rougher surface, higher hardness, higher brittleness and lower ability to withstand bending ${ }^{40)}$.
NRCA also detected minor amounts of copper in G\&H and cobalt in Azdent (Table 2), which is not surprising. Copper is known to sometimes present as residual element, and may be added to produce precipitation hardening or to enhance corrosion resistance. As for cobalt, there is normally a residual cobalt content in the nickel used in producing austenitic $\mathrm{SSs}^{11}$. Because of NRCA's sensitivity to isotopes, the stable ${ }^{56} \mathrm{Fe}$ and ${ }^{57} \mathrm{Fe}$ were detected that constituted the major iron composition in both brands of archwires. One anomaly was noticed here that no nickel nor chromium was detected in the G\&H sample, which we attribute partially to the lower counting statistics of its NRCA spectrum. After all, NRCA is a reliable non-invasive complementary bulk compositional analytical tool, with special attribute of isotope sensitivity and the ability to detect trace elements not detectable by EDX.

The unit cell parameters obtained from ND measurements (Table 3) show that both samples have duplex structure containing body-centered cubic $\alpha$ ' martensite accompanying the expected face-centered cubic $\gamma$ austenite. The $\alpha^{\prime}$ martensite is different from the common body-centered tetragonal $\alpha$ martensite in carbon steels that forms from quenching the austenite. The martensite discovered here is due to a displacive, diffusionless phase transformation where the martensitic phase forms from the metastable austenite $^{41)}$ as a result of the work-hardening imposed by the proprietary cold-working associated with the wire manufacture, which is also known as strain-induced martensite formation ${ }^{42}$. This martensite formation proceeds by the small cooperative movements of the atoms, in a homogeneous lattice deformation fashion combined with rigid-body rotation ${ }^{43)}$. As a result, the chemical composition and atomic order remain the same but the crystal symmetry and volume change. The determined martensite weight fraction of the G\&H sample is relatively high but is comparable with the 56$82 \%$ volume range previously determined with $\mathrm{XRD}^{20)}$.

Since the metastable austenitic phase is very desirable for the ductility and corrosion resistance varying means have been applied to stabilize this phase. These include adding alloying elements, e.g. carbon, nickel and manganese, reducing stacking fault energy, heat treatments, etc. ${ }^{25)}$. Although the determination with EDX is semi-quantitative, Azdent's higher Mn content may partially account for the higher austenite fraction, for the martensite phase transformation would be harder to take place. If the higher surface carbon content determined for $\mathrm{G \& H}$ is due to surface carbides formation, the bulk carbon content would be reduced which then makes the martensite phase transformation easier to take place. Indeed, when the samples were prepared for EDX measurement, the G\&H wires felt harder and more brittle to cut. The higher martensite content would explain this. Future research will focus on correlating the metallurgical structures with physical and mechanical properties.

The phases present in the as-received wires are the consequence of the alloy composition and manufacturing 
processes $^{16)}$, and ironically these two pieces of information are usually kept as a commercial secret. The analyses done here have helped to reveal the alloy composition. It is impossible at this point to retrieve the manufacturing processes. However, it can be concluded that the excessive cold-working and inadequate thermal treatment have resulted in higher degree of martensite transformation in $\mathrm{G} \& \mathrm{H}$ wires

In Fig. 4 insets the two samples exhibited the same series of diffraction peaks at the same positions ( $d$-spacings) arising from neutrons being diffracted by austenite, martensite, aluminium (sample wrapping material), superimposing at some positions. The difference as plotted in Fig. 4 is the result of peak intensity difference due to the varying phase compositions in the two samples. In order to highlight these differences, the main austenite diffraction peaks at $\sim 0.8, \sim 1.08$ and $\sim 1.27 \AA$ are labelled in Fig. 4 . These peaks appear more intense for Azdent because Azdent, as has been determined by Rietveld refinement, contains more austenite (93.38\%) than G\&H (54.33\%).

The fitting in Fig. 4 covered all the diffraction peak positions but the intensities at few positions are not adequate, arising from the occurrence of texture. Texture is the preferred orientation of crystallites and is an intrinsic characteristic that influences physical properties of materials. Texture in metals is related with the thermal-mechanical history. For a polycrystalline material, the intensity recorded at certain orientation is proportional to the fraction of the crystalline phase whose plane is in the reflection geometry. At a pulsed neutron source detector panels cover large angular range thus diffraction spectra from crystals in different orientations are recorded simultaneously. The use of a large number of detectors on INES provides full diffraction patterns and a full range of d-spacings with high resolutions. Although texture determination is not the focus of the current investigation, with the general knowledge in mind that the preferred orientation is along the axis of the wires ${ }^{20)}$ the placement of the sample was made such that the neutron beam direction is perpendicular to the axis. Nevertheless, since each crystal structure has distinct neutron diffraction pattern and the influence of texture is only the change of peak intensity ${ }^{44,45)}$, the quantification of the phases present in the samples with ND is reliable and accurate.

\section{CONCLUSION}

Metallurgical structures of two commercial stainless steel orthodontic archwires were measured in the asreceived form with novel neutron diffraction techniques. It was discovered that both alloys had bi-phase structures where there was $45.67 \%$ martensite in G\&H and 6.62\% in Azdent in addition to the austenite. Simultaneous determination of atomic/isotopic compositions with NRCA complemented the semiquantitative measurement with EDX. Together these results contribute to fill the void of the literature.

Since the martensite has both advantage and disadvantage, the ability to measure and control the relative proportions of both phases is thus essential for clinical practice and materials research. Compared to XRD, ND is a fast, straightforward and reliable metallurgical analytical method and are suitable even for the study of strongly-oriented orthodontic archwires. The pioneering application of neutron spectroscopy opens up new avenues for research in the field of materials for dentistry and beyond.

Future focus will be to correlate the metallurgical structures determined with neutron techniques with physical and mechanical properties for all alloy types, keeping in mind that structure determines property.

\section{ACKNOWLEDGMENTS}

This work was supported by the doctorate scholarship in Materials for Health, Environment and Energy of the department of Chemical Science and Technologies and the postgraduate scholarship of the Department of Clinical Sciences and Translational Medicine of University of Rome Tor Vergata. The CNRSTFC Agreement [2014-2020] on scientific research collaboration at the ISIS spallation neutron source within the PANAREA project also provided funding for neutron beam time. We are grateful to professor Gregory Chass of Queen Mary University of London for insightful discussions.

\section{REFERENCES}

1) Harrison A. In: Understanding Stainless Steel. New Centenary ed. Sheffield: British Stainless Steel Association; 2013.

2) Sedriks AJ. In: Corrosion of Stainless Steel, 2. New York: John Wiley and Sons, Inc.; 1996.

3) Ryan MP, Williams DE, Chater RJ, Hutton BM, McPhail DS. Why stainless steel corrodes. Nature 2002; 415: 770-774.

4) Kusy RP.A review of contemporary archwires: their properties and characteristics. Angle Orthod 1997; 67: 197-208.

5) Fields HW, Jr Sarver DM, Proffit WR. In: Contemporary Orthodontics. Elsevier Health Sciences; 2007.

6) Park HY, Shearer TR. In vitro release of nickel and chromium from simulated orthodontic appliances. Am J Orthod 1983; 84: 156-159.

7) Okamoto G. Passive film of $18-8$ stainless steel structure and its function. Corros Sci 1973; 13: 471-489.

8) Kapila S, Sachdeva R. Mechanical properties and clinical applications of orthodontic wires. Am J Orthod Dentofacial Orthop 1989; 96: 100-109.

9) Daems J, Celis JP, Willems G. Morphological characterization of as-received and in vivo orthodontic stainless steel archwires. Eur J Orthod 2009; 31: 260-265.

10) Elgiloy Company. Elgiloy: the cobalt-nickel alloy. Elgin, IL: Elgiloy Company; undated promotional literature, circa 1970.

11) Andreasen GF, Hilleman TB. An evaluation of 55 cobalt substituted Nitinol wire for orthodontics. J Am Dent Assoc 1971; 82: 1373-1375.

12) Burstone CJ, Goldberg AJ. Beta titanium: a new orthodontic alloy. Am J Orthod 1980; 77: 121-132.

13) Brantley WA, Eliades T. In: Orthodontic Materials: Scientific and Clinical Aspects Stuttgart: Thieme; 2001.

14) Yoshikawa DK, Burstone CJ. Flexure modulus of orthodontic stainless steel wires. J Dent Res 1981; 60: 139-145. 
15) Kusy RP, Dilley GJ. Elastic modulus of a triple stranded stainless steel arch wire via three and four point bending. J Dent Res 1984; 63: 1232-1240.

16) Tian K, Darvell BW. Determination of flexural modulus of elasticity of orthodontic archwires. Dent Mater 2010; 26: 821829 .

17) Meling TR, Ødegaard J, Meling E. On mechanical properties of square and rectangular stainless steel wires tested in torsion. Am J Orthod Dentofacial Orthop 1997; 111: 310-320.

18) Acharya KA, Jayade VP. Metallurgical properties of stainless steel orthodontic archwires: a comparative study. Trends Biomater Artif Organs 2005; 18125-18136.

19) Khier SE, Brantley WA, Fournelle RA. Structure and mechanical properties of as-received and heat-treated stainless steel orthodontic wires. Am J Orthod Dentofacial Orthop 1988; 93: 206-212.

20) Cheary RW, Ma-Sorrell Y. Quantitative phase analysis by $\mathrm{X}$-ray diffraction of martensite and austenite in strongly oriented orthodontic stainless steel wires. J Mater Sci 2002; 35: 1105-1113.

21) Izquierdo PP, de Biasi RS, Elias CN, Nojima LI. Martensitic transformation of austenitic stainless steel orthodontic wires during intraoral exposure. Am J Orthod Dentofacial Orthop 2010; 138: 714.e1-5.

22) Goldberg AJ, Vanderby R, Burstone CJ. Reduction in the modulus of elasticity in orthodontic wires. J Dent Res 1977; 56: 1227-1231.

23) Asgharnia MK, Brantley WA. Comparison of bending and tension tests for orthodontic wires. Am J Orthod 1986; 89: 228-236.

24) Fewster PF. X-ray analysis of thin films and multilayers. Rep Prog Phys 1996; 59: 1339-1407.

25) Breda M, Brunelli K, Grazzi F, Scherillo A, Calliari I. Effects of cold rolling and strain-induced martensite formation in a SAF 2205 duplex stainless steel. Metallur Mater Trans A 2015; 46: 577-586.

26) Slattery GF, Windsor CG. The application of neutron diffraction to a study of phases in type 316 stainless steel weld metals. J Nucl Mater 1983; 118: 165-178.

27) Woo W, Em V, Seong BS, Shin S, Mikula P, Joo J, Kang MH. Effect of wavelength-dependent attenuation on neutron diffraction stress measurements at depth in steels. J Appl Crys 2011; 44: 747-754.

28) Imberti S, Andreani C, Garbuio V, Gorini G, Pietropaolo A, Senesi R, Tardocchi M. Resolution of the VESUVIO spectrometer for high-energy inelastic neutron scattering experiments. Nucl Instrum Methods Phys Res Sect A 2005; 552: $463-476$.

29) Goldstein JI, Newbuty DE, Joy DC, Lyman CE, Echlin P, Lifshin E, Sawyer L, Michael JR. Scanning Electron Microscopy and X-ray Microanalysis. Third Ed. New York: Springer; 2003.

30) Postma H, Blaauw M, Bode P, Mutti P, Corvi F, Siegler P. Neutron-resonance capture analysis of materials. J
Radioanalyt Nucl Chem 2001; 248: 115-120.

31) Cippo EP, Borella A, Gorini G, Kockelmann W, Moxon M, Postma H, Rhodes NJ, Schillebeckx P, Schooneveld EM, Tardocchi M, Dusz K, Hajnal Z, Biro K, Porcinai S, Andreani C, Festa G. Imaging of cultural heritage objects using neutron resonances. J Anal At Spectrom 2011; 26: 992-999.

32) Tardocchi M, Gorini G, Pietropaolo A, Andreani C, Senesi R, Rhodes NJ, Schooneveld EM. YAP scintillators for resonant detection of epithermal neutrons at pulsed neutron sources. Rev Sci Instrum 2004; 75: 4880-4890.

33) Festa G, Pietropaolo A, Grazzi F, Sutton LF, Scherillo A, Bognetti L, Bini A, Barzagli E, Schooneveld E, Andreani C. Simultaneous and integrated neutron-based techniques for material analysis of a metallic ancient flute. Meas Sci Technol 2013; 24: 095601.

34) Festa G, Pietropaolo A, Grazzi F, Barzagli E, Scherillo A, Schooneveld EM. Neutron diffraction measurements at the INES diffractometer using a neutron radiative capture based counting technique. Nucl Instrum Methods Phys Res Sect A 2011: 654: 373-376.

35) Festa G, Arcidiacono L, Pappalardo A, Minniti T, Cazzaniga C, Scherillo A, Andreani C, Senesi R. Isotope identification capabilities using time resolved prompt gamma emission from epithermal neutrons. J Instrum 2016; 11: C03060.

36) Pietropaolo A, Festa G, Grazzi F, Barzagli E, Scherillo A, Schooneveld EM, Civita F. A multitask neutron beam line for spallation neutron sources. Europhys Lett 2011; 95: 48007.

37) Mughabghab SF. In: Neutron Cross Sections, Volume 1, Neutron Resonance Parameters and Thermal Cross Sections. Orlando: Academic Press; 1984.

38) Larson AC, von Dreele RB. General Structure Analysis System (GSAS). Los Alamos National Laboratory Report LAUR 1994; 86-748.

39) Toby BH. EXPGUI, a graphical user interface for GSAS. J Appl Crystallogr 2001; 34: 210-213.

40) Pelsue BM, Zinelis S Bradley TG, Berzins DW, Eliades T, Eliades G. Structure, composition, and mechanical properties of Australian orthodontic wires. Angle Orthod 2009; 79: 97 101.

41) Porter DA, Easterling KE, Sherif MY. Phase Transformations in Metals and Alloys. Third edition. Boca Raton: CRC Press; 2009.

42) Talonen J, Hänninen H, Nenonen P, Pape G. Effect of strain rate on the strain-induced $\gamma \rightarrow \alpha^{\prime}$-martensite transformation and mechanical properties of austenitic stainless steels. Metallur Mater Trans A 2005; 36: 421-432.

43) Nishiyama Z. In: Martensitic Transformation. New York: Academic Press; 1978.

44) Wenk HR. (Ed.) In: Preferred Orientation in Deformed Metals and Rocks -An Introduction to Modern Texture Analysis. New York: Academic Press; 1985.

45) Wenk HR, Van Houtte P. Texture and anisotropy. Report Prog Phys 2004; 67: 1367-1428. 